\title{
A influência dos inibidores seletivos da recaptação de serotonina, fluoxetina sertralina e citalopram no processo de regeneração óssea
}

The influence of the selective serotonin reuptake inhibitors fluoxetine, sertraline and citalopram on the regeneration process

La influencia de los inhibidores selectivos de la recaptación de serotonina fluoxetina, sertralina y citalopram en el proceso de regeneración

Leticia da Costa Siqueira ORCID: https://orcid.org/0000-0003-0048-1273 Universidade Federal de Alfenas, Brasil E-mail:leticiacsiqueira21@gmail.com

Karinne da Costa Souza ORCID: https://orcid.org/0000-0002-5139-7445 Universidade Federal de Alfenas, Brasil E-mail: karinne_souza24@hotmail.com

Micaella Rodrigues Guimarães Leite ORCID: https://orcid.org/0000-0001-7779-0395 Universidade Federal de Alfenas, Brasil E-mail:rodriguesmicaella99@gmail.com Ítalo Augusto Silva Ferreira ORCID: https://orcid.org/0000-0002-6707-2178 Universidade Federal de Alfenas, Brasil E-mail:italoaugustos@hotmail.com

Ana Luiza Dias Leite de Andrade ORCID: https://orcid.org/0000-0002-0068-9050 Universidade Federal de Alfenas, Brasil E-mail:ana.andrade@unifal-mg.edu.br Alessandra Esteves

ORCID: https://orcid.org/0000-0002-0228-2940 Universidade Federal de Alfenas, Brasil E-mail:aesteves015@gmail.com

Wagner Costa Rossi Junior

ORCID: https://orcid.org/0000-0003-1901-9978 Universidade Federal de Alfenas, Brasil

E-mail: wagnerunifal@gmail.com

\section{Resumo}

Embora a regeneração do tecido ósseo seja um processo bem definido, ainda são observadas complicações inerentes ao tratamento de fraturas, sendo um deles a participação da serotonina na formação e remodelação óssea. Esta é um hormônio responsável pela regulação de vários processos fisiológicos e está correlacionada com a etiologia da depressão, cujo tratamento se dá, especialmente, pelo uso de inibidores seletivos da recaptação de serotonina (ISRS), os quais se relacionam com aumento ao risco de fratura e perda óssea. Assim, o objetivo deste estudo foi analisar a ação da Fluoxetina, Sertralina e do Citalopram no processo de regeneração óssea. Foram utilizados 35 ratos Wistar, nos quais foram confeccionados defeitos ósseos de 2 a $3 \mathrm{~mm}$ de comprimento na fíbula. Os animais receberam Cloridrato de Fluoxetina 60 dias antes da confecção da fratura, e Cloridrato de Sertralina e Bromidrato de Citalopram 40 dias antes, e se prolongou por mais 30 dias após o procedimento. Os animais controle receberam solução salina. Os resultados mostram que o processo de regeneração do defeito ósseo se deu de maneira mais efetiva nos animais pertencentes ao grupo controle, quando comparado aos demais grupos tratados. Os mesmos dados foram observados quanto à taxa sérica de fosfatase alcalina, diferente estatisticamente quando comparada com os animais tratados com os ISRS. Estes dados permitem sugerir que a Fluoxetina, a Sertralina e o Citalopram parecem interferir negativamente no processo de regeneração óssea, levando a um atraso e a não consolidação total das fraturas com perda óssea.

Palavras-chave: Sertralina; Fluoxetina; Citalopram; Regeneração óssea; Consolidação da fratura.

\section{Abstract}

Although bone tissue regeneration is a well-defined process, complications inherent to the treatment of fractures are still observed, one of them being the participation of serotonin in bone formation and remodeling. This is a hormone responsible for the regulation of several physiological processes and is correlated with the etiology of depression, 
whose treatment is given, especially, through the use of selective serotonin reuptake inhibitors (SSRI), which are related to an increased risk of fracture and bone loss. Thus, the aim of this study was to analyze the action of Fluoxetine, Sertraline and Citalopram in the bone regeneration process. Thirty-five Wistar rats were used, in which bone defects of 2 to $3 \mathrm{~mm}$ in length were made in the fibula. The animals received Fluoxetine Hydrochloride 60 days before the fracture was made, and Sertraline Hydrochloride and Citalopram Hydrochloride 40 days before, and continued for another 30 days after the procedure. Control animals received saline solution. The results show that the bone defect regeneration process occurred more effectively in animals belonging to the control group, when compared to the other treated groups. The same data were observed regarding the serum alkaline phosphatase rate, statistically different when compared to animals treated with SSRIs. These data allow us to suggest that Fluoxetine, Sertraline and Citalopram seem to negatively interfere in the bone regeneration process, leading to a delay and non-complete consolidation of fractures with bone loss.

Keywords: Sertraline, Fluoxetine; Citalopram; Bone regeneration; Fracture healing.

\section{Resumen}

Si bien la regeneración del tejido óseo es un proceso bien definido, aún se observan complicaciones inherentes al tratamiento de las fracturas, siendo una de ellas la participación de la serotonina en la formación y remodelación ósea. Esta es una hormona responsable de la regulación de varios procesos fisiológicos y se correlaciona con la etiología de la depresión, cuyo tratamiento se da, especialmente, mediante el uso de inhibidores selectivos de la recaptación de serotonina (ISRS), que se relacionan con un mayor riesgo de fractura y pérdida ósea. Así, el objetivo de este estudio fue analizar la acción de Fluoxetina, Sertralina y Citalopram en el proceso de regeneración ósea. Se utilizaron treinta y cinco ratas Wistar, en las que se realizaron defectos óseos de 2 a $3 \mathrm{~mm}$ de longitud en el peroné. Los animales recibieron clorhidrato de fluoxetina 60 días antes de que se produjera la fractura, y clorhidrato de sertralina y clorhidrato de citalopram 40 días antes, y continuaron durante otros 30 días después del procedimiento. Los animales de control recibieron solución salina. Los resultados muestran que el proceso de regeneración del defecto óseo ocurrió de manera más efectiva en los animales que pertenecen al grupo de control, en comparación con los otros grupos tratados. Se observaron los mismos datos con respecto a la tasa de fosfatasa alcalina sérica, estadísticamente diferente en comparación con los animales tratados con ISRS. Estos datos nos permiten sugerir que la fluoxetina, la sertralina y el citalopram parecen interferir negativamente en el proceso de regeneración ósea, provocando un retraso y consolidación incompleta de las fracturas con pérdida ósea.

Palabras clave: Sertralina; Fluoxetina; Citalopram; Regeneraciòn ósea; Curación de fractura.

\section{Introdução}

Embora a regeneração do tecido ósseo seja um processo bem definido, ainda são observadas complicações inerentes ao tratamento de fraturas e falhas ou defeitos ósseos, pois alguns fatores ainda não são totalmente elucidados ou conclusivos. Um deles é a ação da serotonina na formação e remodelação óssea (Yadav et al., 2008; Yadav et al., 2009).

A molécula de serotonina é sintetizada por dois genes diferentes em dois diferentes locais (Tph1 - serotonina intestinal; Tph2 - serotonina encefálica) e, surpreendentemente, desempenham funções antagônicas no metabolismo ósseo. Quando produzida perifericamente, atua como um hormônio para inibir a formação óssea. Em contraste, quando produzida no tronco encefálico, atua como um neurotransmissor, para exercer um efeito dominante no acúmulo de massa óssea, pelo aumento na formação e limitação da reabsorção óssea. O efeito da serotonina na biologia óssea pode ser aproveitado farmacologicamente para tratar doenças como a osteoporose, embora ainda não tenham sido esclarecidas todas as funções da serotonina (5HT - 5 hidroxitriptamina) na formação e remodelação óssea (Ducy \& Karsenty, 2018).

A deficiência de serotonina está diretamente relacionada com alterações de humor, com destaque para a depressão, condição bastante comum nos dias de hoje, associada com incapacitação funcional e comprometimento da saúde física e mental. Muitas vezes, o paciente deprimido não recebe tratamento suficientemente adequado e específico, acarretando em piora considerável. Um dos tratamentos mais preconizados é o uso de inibidores seletivos da recaptação de serotonina (ISRS), os quais aumentam a disponibilidade desta substância nas fendas sinápticas e potencializam sua ação, reduzida na depressão (Fleck, et al., 2009; Santiago et al., 2013).

Assim, como a literatura ainda não esclareceu completamente o papel da serotonia no metabolismo ósseo e, tão pouco das substâncias que interferem na fisiologia da 5HT, o objetivo deste estudo foi avaliar os efeitos dos inibidores seletivos da 
recaptação de serotonina fluoxetina, sertralina e citalopram, no processo de reparo de fraturas com perda óssea em fíbulas de ratos.

\section{Metodologia}

Foram utilizados 35 ratos (rattus norvegicus) machos da linhagem Wistar, provenientes do Biotério da Universidade Federal de Alfenas UNIFAL- MG, os quais foram alojados em caixas contendo três animais cada uma, tratados com ração comercial e água à vontade e mantidos em ciclo de 12 horas claro-escuro. O trabalho foi aprovado pelo CEUA-UNIFAL com protocolo 27/2019. Os animais foram divididos em sete grupos experimentais (n=5): Grupo I (G1 - controle sem nenhum tratamento); Grupo II (G2 - tratados com cloridrato de fluoxetina e não submetidos à fratura; Grupo III (G3 - submetidos à fratura, porém sem medicação); Grupo IV (G4 - tratados com cloridrato de fluoxetina até o dia anterior à cirurgia); Grupo V (G5 - tratados com cloridrato de fluoxetina até 30 dias após a confecção das fraturas); Grupo VI (G6 - tratados com cloridrato de sertralina); e Grupo VII (G7 - tratados com bromidrato de citalopram).

O tratamento consistiu na administração de $10 \mathrm{mg} / \mathrm{kg} / \mathrm{dia}$ de cloridrato de fluoxetina (Prozac), $10 \mathrm{mg} / \mathrm{kg} / \mathrm{dia}$ de cloridrato de sertralina e $20 \mathrm{mg} / \mathrm{kg} / \mathrm{dia}$ de bromidrato de citalopram, os quais foram diluídos em solução fisiológica estéril e administrados via intraperitoneal (Cuquetto et al., 2012; Fernandes et al., 2012; Refsgaard et al., 2016; Gill et al., 2017; Atli et al., 2017); Li, et al., 2019). Os grupos sem ISRS (G1 e G3) foram submetidos à injeção intra-peritoneal de solução fisiológica estéril para mimetizar o estresse. O início da administração do cloridrato de fluoxetina ocorreu sessenta dias antes do procedimento cirúrgico, para que se caracterizasse o uso crônico da medicação. Para o cloridrato de sertralina e o bromidrato de citalopram, a administração se iniciou com quarenta dias antes do procedimento cirúrgico. A medicação foi administrada até o dia anterior à eutanásia, que se deu 30 dias após a criação dos defeitos ósseos. As cirurgias foram realizadas sob anestesia com uma mistura de cloridrato de Ketamina (Ketalar ${ }^{\circledR}-50 \mathrm{mg} / \mathrm{ml}$ ) e cloridrato de xilazina (Rompum ${ }^{\circledR}-2 \mathrm{~g} / 100 \mathrm{ml}$ ), na dose de $0,20 \mathrm{ml} / 100 \mathrm{~g}$ de peso e $0,10 \mathrm{ml} / \mathrm{kg}$ de peso, respectivamente. Ao nível da união do terço proximal com o terço médio da diáfise, foi retirado um fragmento de dois (2) a três (3) milímetros de osso, restando sempre dois cotos de osso, um proximal e outro distal; este intervalo de $1 \mathrm{~mm}$ se deu devido à grande dificuldade de precisão do defeito, sobretudo para evitar qualquer trauma extra aos animais e, de acordo com a literatura, não influencia na taxa de regeneração (Rossi Jr, 2002; Mir et al., 2013). As fíbulas foram radiografadas, utilizando-se películas oclusais com tempo de exposição aos raios x de 0,8 segundos e, no sangue coletado, foi dosada a enzima fosfatase alcalina, a qual é considerada um excelente marcador bioquímico para mostrar a taxa de metabolismo ósseo. Os valores obtidos foram submetidos a análise estatística pelo teste ANOVA two Way no software Graph Pad Prism versão 8.0, com nível de significância de 5\%.

\section{Resultados}

Este estudo evidenciou que os inibidores seletivos da recaptação de serotonina são substâncias que interferem de forma negativa na taxa de regeneração óssea quando utilizados de forma crônica. A Tabela 1 mostra claramente a taxa de regeneração. Nos animais submetidos ao tratamento de fratura com as três medicações, não houve regeneração óssea em nenhum deles, comparado com o grupo III (fratura sem medicação), no qual quatro apresentaram regeneração total, o que equivale a $80 \%$. O único animal o qual não apresentou total regeneração radiográfica, mostrava pequenos sinais de remodelação com crescimento dos cotos de fratura, pois o defeito mostrava menor área. 
Tabela 1 - Taxa de regeneração dos animais submetidos á fratura.

\begin{tabular}{cccccccc}
\hline & G1 & G2 & G3 & G4 & G5 & G6 & G7 \\
\hline Regenerados & 5 & 4 & 4 & 0 & 0 & 0 & 0 \\
Não Regenerados & 0 & 0 & 1 & 5 & 5 & 5 & 3 \\
Total & 5 & $4 *$ & 5 & 5 & 5 & 5 & $3 *$ \\
\hline
\end{tabular}

* Nestes grupos houve óbito de animais com menor número total. Fonte: Autores.

As figuras 1 e 2 mostram o aspecto radiográfico das pernas dos animais submetidos à fratura. A regeneração foi considerada completa quando houve total consolidação do defeito ósseo e encontro dos dois cotos de fratura. É possível observar que em alguns animais, além de não ter ocorrido a regeneração, houve reabsorção óssea com aumento dos defeitos produzidos cirurgicamente (Figura $1 \mathrm{C}$ e D).

Figura 1 - Aspecto radiográfico das fíbulas esquerdas após trinta dias da confecção do defeito ósseo. A regeneração total (seta amarela mostra calo ósseo); B, C e D mostram defeitos ósseos não regenerados. Animais tratados com fluoxetina. Setas vermelhas indicam a área do defeito ósseo não regenerado.
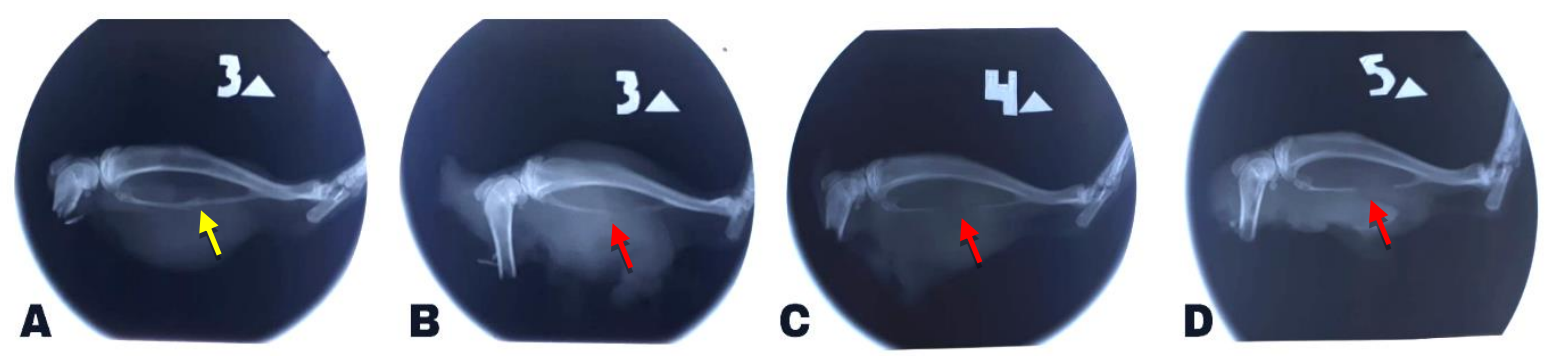

Fonte: Autores.

Figura 2 - Aspecto radiográfico das fíbulas esquerdas após trinta dias da confecção do defeito ósseo. 1 - regeneração total (seta amarela mostra calo ósseo); 2 e 3 mostram defeitos ósseos não regenerados. Animais tratados com sertralina e citalopram. Setas vermelhas indicam a área do defeito ósseo não regenerado.
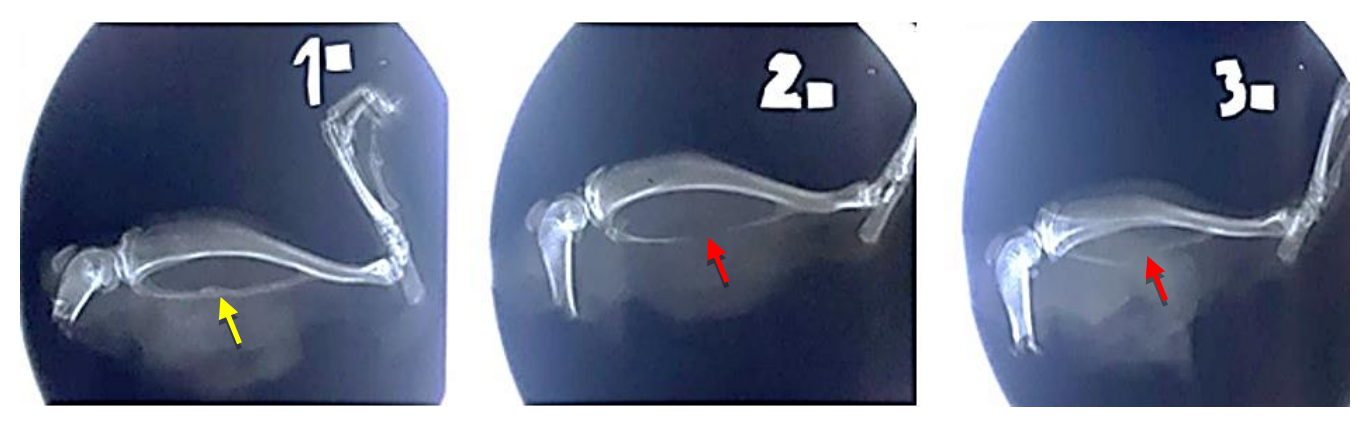

Fonte: Autores.

A dosagem sérica da fosfatase alcalina, a qual é considerada um importante marcador biológico do metabolismo ósseo, mostrou diferenças significativas entre os grupos não tratados com aqueles que utilizaram o cloridrato de fluoxetina $(\mathrm{p}<0,05)$ (Figura 3). Os maiores níveis de fosfatase alcalina observados no grupo G3 em comparação com os demais pode ser 
justificado pelo fato de que tal grupo se submeteu ao procedimento cirúrgico, porém não recebeu nenhum tipo de tratamento, indicando alta produção enzimática necessária à consolidação óssea.

Figura 3 - Resultado bioquímico dos níveis de fosfatase alcalina entre os grupos tratados com cloridrato de fluoxetina. G1 grupo controle; G3 - fratura sem medicação. Todos os grupos foram estatisticamente diferentes de G3; P < 0,05.

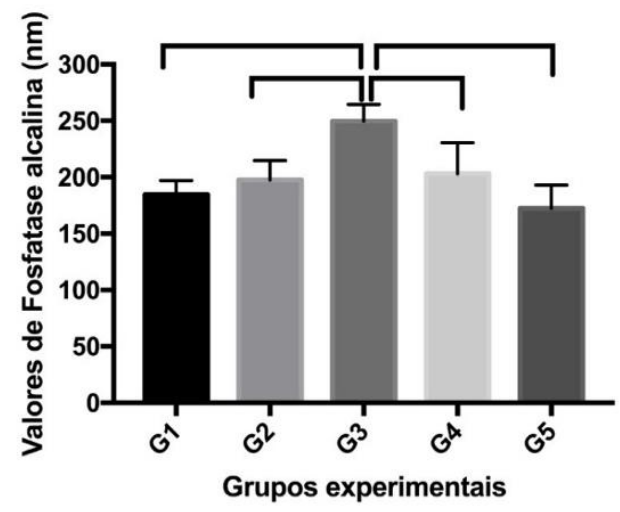

Fonte: Autores.

A dosagem sérica da fosfatase alcalina nos grupos tratados com cloridrato de sertralina e bromidrato de citalopram não mostrou diferenças estatisticamente significativas entre os grupos analisados (Figura 4).

Figura 4 - Valores da taxa sérica de fosfatase alcalina $(\mathrm{P}<0,05)$.

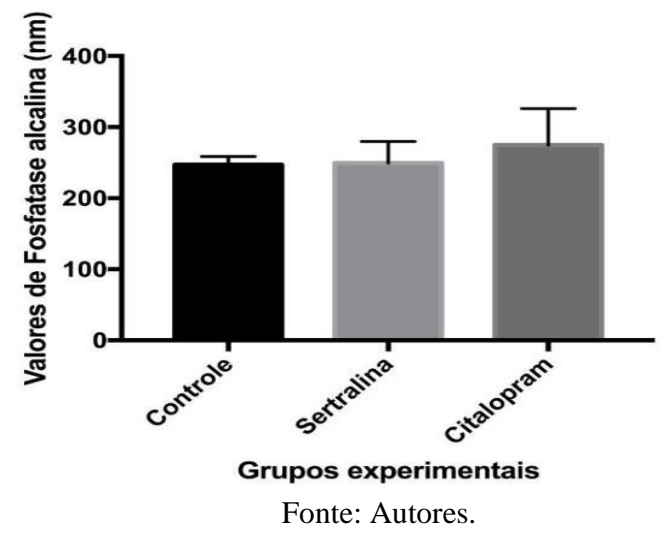

\section{Discussão}

O modelo de fíbulas foi utilizado neste estudo devido à pouca complexidade de se obter o defeito ósseo, sem causar grandes prejuízos locomotores ao animal, pois a fíbula está totalmente inserida à tíbia e, assim, não suporta diretamente o peso do animal (Silva, 2016). Nesse sentido, a criação de defeitos ósseos de tamanho não crítico, servem como excelente modelo para a análise do processo de regeneração.

O tecido ósseo é uma forma altamente especializada do tecido conjuntivo, composto por células e matriz óssea, esta, formada por material extracelular calcificado (Gartner \& Hiatt, 2007; Junqueira \& Carneiro, 2013). Apesar de aparentemente, se comportarem como estruturas estáticas, os ossos são dinâmicos, sendo substituídos por osso recém-depositado, à medida que envelhecem ou sofrem algum dano, além de apresentarem numerosas funções essenciais ao homem e outros vertebrados (Seibel et al., 2006). 
Os principais tipos de células ósseas são osteoblastos, osteoclastos e osteócitos. A atividade conjunta destas células é essencial para a correta fisiologia óssea e fundamental para as duas fases que permitem a remodelação do tecido ósseo (deposição e a reabsorção) durante o crescimento fisiológico ou em processos de regeneração decorrentes de lesões (Lirani, 2004; Garlingo, 2006; Gartner \& Hiatt, 2007; Junqueira \& Carneiro, 2013). Além disso, as superfícies ósseas externa e interna são revestidas, respectivamente, por periósteo e endósteo, constituídos por células osteoprogenitoras e também com função de nutrição óssea (Isola \& Morais, 2012). Defeitos ósseos em fíbulas de ratos com até 2,5 a 3 milímetros, embora comprometam o periósteo, ainda são capazes de regeneração espontânea. Acima deste intervalo há interposição de tecido muscular e o defeito não mais consegue se consolidar. Por isso, neste estudo foram criados defeitos de tamanho não crítico para a análise do processo de regeneração (Rossi, 2002).

Para Ducy (2011), a formação e a reabsorção óssea são dois processos que ocorrem de forma constante e equilibrada, regulados por sinais bastante diversificados, como fatores locais, uma variedade de fatores de crescimento, hormônios e estímulos neurais. Das várias substâncias envolvidas nestes processos, a serotonina neural e periférica mostra-se capaz de interferir e controlar, atuando como neuromediador e hormônio, respectivamente. A serotonina, no cérebro, regula positivamente o acúmulo de massa óssea e a serotonina periférica é um potente inibidor da formação óssea.

A serotonina (5 HT) foi identificada em 1948 como uma molécula presente no soro (serum) e capaz de induzir vasoconstrição (tonin), apesar de atuar como regulador de funções cardiovasculares; talvez seu nome não seja muito adequado, pois exerce uma variedade de outras funções. Conforme o local de produção atua na hemostasia, ansiedade ou no movimento intestinal (Rapport et al., 1948; Ducy \& Karsently, 2010).

A serotonina cerebral é um neurotransmissor bastante conhecido, estando relacionada com vários transtornos afetivos, destacando-se a depressão. Sua participação no metabolismo do osso é mais recente e a ligação se dá em decorrência da inervação simpática no tecido ósseo, cuja atividade atuaria no processo de remodelação reduzindo a formação óssea. Assim, a serotonina cerebral desempenharia ação oposta em relação à serotonina periférica. Porém este mecanismo ainda não é bastante elucidado e se faz urgente maiores entendimentos, pela quantidade de inibidores seletivos da receptação de serotonina utilizados nos dias de hoje, desde a população mais jovem, até pessoas com mais idade. Embora, a princípio, se pensava em aumento da taxa de formação óssea pela inibição do sistema nervoso simpático pela 5HT cerebral, o uso crônico dos ISRS acarreta em redução considerável da massa óssea (Yadav et al., 2008; Yadav et al., 2009). Novamente os resultados observados neste estudo reforçam a ideia de que o uso crônico destes medicamentos podem comprometer de forma negativa o processo de regeneração do tecido ósseo.

O processo de remodelação dos ossos desenvolve-se com base em dois processos antagônicos, mas acoplados: a formação e a reabsorção óssea. $\mathrm{O}$ acoplamento dos dois processos permite a renovação e remodelação óssea e é mantido em longo prazo por um complexo sistema de controle que inclui hormônios, fatores físicos e fatores humorais locais (Henn, 2010). A falha desse mecanismo resulta em diversas alterações que podem ser avaliadas através dos marcadores de rotatividade (Williams et al., 2018). A dosagem sérica de fosfatase alcalina realizada neste estudo mostrou diferenças significativas quando se comparou animais fraturados sem medicação e com aqueles que receberam cloridrato de fluoxetina. Estes tiveram uma menor quantidade sérica da enzima, condição que também pode ter se somado à maior quantidade de serotonina, contribuindo assim para a não regeneração óssea

Atualmente os ISRS têm sido os antidepressivos de primeira escolha para tratamento de inúmeras desordens psíquicas. Algumas das drogas pertencentes a esse grupo são citalopram, a sertralina, a fluoxetina e o escitalopram. Embora compartilhem o mesmo mecanismo de ação, os ISRS são estruturalmente distintos, com significativas diferenças no perfil farmacodinâmico e farmacocinético (Telles-Correa et al., 2007). 
De acordo com Brandão (2015), somando aos ISRSs, a própria depressão, motivo pelo qual estes são prescritos, leva a alterações nos sistemas de comportamento e neuroendócrinos, causando diminuição da densidade mineral óssea (DMO) através da diminuição dos níveis de osteocalcina. Desse modo, tanto o mecanismo fisiológico da depressão, quanto a utilização de fármacos antidepressivos parecem ter influência no metabolismo ósseo. Para Vestergaard et al. (2008), a maioria dos ISRSs está associado a um aumento dose-dependente no risco de fraturas, presente também com o tempo prolongado de uso. O aumento do risco de fraturas foi relacionado ao impacto do medicamento no sistema transportador de serotonina.

Hodge et al. (2013) investigaram as ações da classe dos ISRS sobre a formação e função de osteoclastos e osteoblastos humanos e revelou atividade apoptótica potente. Todos os inibidores seletivos da recaptação de serotonina inibiram a formação de osteoclastos e reabsorção na ordem de potência: sertralina > fluoxetina > paroxetina > fluvoxamina > citalopram. Os resultados deste estudo corroboram estes dados, porém questiona quanto à ordem de potência, pois a fosfatase alcalina sérica foi mais comprometida no grupo usuário de fluoxetina. Além disso, o que também chama a atenção é a taxa de óbito nos animais usuários do bromidrato de citalopram, a qual foi bem elevada. Isso vem de encontro com os dados de Tarabar et al. (2008), os quais estabelecem efeito cardiotóxico dessa substância.

O cloridrato de fluoxetina é considerado o antidepressivo mais utilizado na prática clínica em todo mundo, sendo capaz de inibir de forma potente e seletiva a recaptação de serotonina. O efeito da fluoxetina em ossos longos como fêmur ou tíbia foi a inibição do crescimento normal dos ossos por reduzir a massa óssea total, o que provocou efeitos deletérios na arquitetura destes tecidos (Santiago et al., 2013). Estes dados são corroborados pelo estudo de Warden et al. (2005) que observou uma formação óssea reduzida e um aumento no processo de reabsorção e pelos resultados deste estudo, os quais mostraram sério comprometimento na regeneração óssea.

Os resultados desta pesquisa referentes à utilização de cloridrato de sertralina, corroboram com os achados de Howie et al. (2018), que evidenciaram alterações significativas como a diminuição da espessura e quantidade trabecular e a morfologia dos osteoclastos no processo de consolidação óssea. Somado a isso, os estudos de Abu Nada (2017) e Abu Nada et al. (2018) demonstraram que tal efeito comum aos inibidores seletivos de recaptação de serotonina e em específico a sertralina, se deve ao aumento do número de osteoclastos e diminuição do número de osteoblastos por meio de implicações nos processos de hemostasia, resposta inflamatória e remodelação óssea. Dessa forma, assim como nestes estudos, observa-se que o cloridrato de sertralina interferiu negativamente na cicatrização da ferida óssea nas fíbulas de ratos, ocasionando alterações no reparo e regeneração ou ainda impedindo este mecanismo.

Para Feighner \& Overo (1999), o citalopram é o mais seletivo inibidor da recaptação de serotonina, e com estrutura química diferente de outros ISRS. Porém, da mesma forma quanto às outras substâncias, também pode ter ação deletéria no tecido ósseo. Segundo Richter et al. (2014) o uso crônico está relacionado ao desenvolvimento de osteoporose. Além disso, de acordo com Cray et al. (2014), quando utilizado durante o período gestacional, está associado a alterações celulares e morfológicas no complexo craniofacial.

Os estudos com esta classe de medicação, embora sejam numerosos, ainda não elucidam totalmente a forma de ação no metabolismo ósseo. O que se constata é que os mesmos resultados deste trabalho, corroboram com resultados apresentados na literatura, ou seja, os ISRS são substâncias que interferem de forma negativa no processo de regeneração óssea e nos mecanismos fisiológicos de remodelação e crescimento dos ossos, quando utilizados de forma crônica ou abusiva. Esta é uma condição bastante comum nos dias atuais, pois grande parte da população apresenta alterações emocionais ou depressivas, as quais têm como primeira escolha de tratamento os ISRS. Aliado a este fato, é fundamental que os profissionais da saúde, especialmente médicos ortopedistas e cirurgiões dentistas que realizam constantemente procedimentos em osso, tenham conhecimento dessas informações e incorporem na anamnese perguntas referentes ao uso ou não destes medicamentos, pois o sucesso dos procedimentos podem ter direta relação com a substância utilizada pelo paciente. Trabalhos mostram efeitos 
deletérios do uso crônico de fluoxetina, causando prejuízo no desenvolvimento mandibular de ratos, desenvolvimento e remodelação do osso alveolar, amelogênese, pulpogênese, odontogênese e periodontogênese (Gonçalves, 2013; Matos, 2011; Jaegger, 2015; Fonseca, 2020; Regueira, 2013; Riksen et al., 2010). O que suscita que haja extrema importância do cuidado clínico-odontológico e ortopédico para com pacientes usuários desta classe de medicamentos, uma vez que podem interferir negativamente em diversos procedimentos, como na osseointegração de implantes dentários, extrações, movimentação ortodôntica, próteses ortopédicas, síntese de fraturas, ou seja, procedimentos que requeiram qualidade óssea, a qual estará seriamente comprometida (Vieira et al., 2018; Yildirim \& Eralp, 2021).

\section{Conclusão}

Considerando os resultados obtidos neste estudo, o qual analisou radiograficamente a regeneração de defeitos ósseos criados em fíbulas de ratos e tratados com os antidepressivos cloridrato de fluoxetina, cloridrato de sertralina e bromidrato de citalopram, a regeneração não ocorreu. Estas substâncias interferem negativamente no processo de regeneração óssea, além de interferir na taxa de fosfatase alcalina sérica, sendo muito interessante que os profissionais que exercem suas atividades manipulando de alguma forma o tecido ósseo, especialmente ortopedistas e cirurgiões dentistas, tenham maior cuidado e atenção no tratamento de pacientes que utilizam essas substâncias.

\section{Agradecimentos}

Agradecemos ao Departamento de Anatomia (DAnat) da Universidade Federal de Alfenas (Unifal-MG) por viabilizar a realização dos experimentos.

\section{Referências}

Abu Nada, L. (2017). The effect of selective serotonin reuptake inhibitors on bone healing and titanium implant osseointegration. EScholarship@ McGill. https://escholarship.mcgill.ca/concern/theses/h702q874b

Abu Nada, L., Al Subaie, A., Mansour, A., Wu, X., Abdallah, M., Al-Waeli, H., Ersheidat, A., Stone, L. S., Murshed, M., \& Tamimi, F. (2018). The antidepressant drug, sertraline, hinders bone healing and osseointegration in rats' tibiae. Journal of Clinical Periodontology, 45(12), 1485-1497. https://doi.org/10.1111/jcpe.13015

Atli, O., Baysal, M., Aydogan-Kilic, G., Kilic, V., Ucarcan, S., Karaduman, B., \& Ilgin, S. (2017). Sertraline-induced reproductive toxicity in male rats: evaluation of possible underlying mechanisms. Asian Journal of Andrology, 19(6), 672. https://doi.org/10.4103/1008-682x.192637

Brandão, M. M. C. (2015) Influência do uso de fármacos anti-depressivos na colocação de implantes dentários. Cidade do Porto, 2015.

Cray, J. J., Weinberg, S. M., Parsons, T. E., Howie, R. N., Elsalanty, M., \& Yu, J. C. (2014). Selective serotonin reuptake inhibitor exposure alters osteoblast gene expression and craniofacial development in mice. Birth Defects Research Part A: Clinical and Molecular Teratology, 100(12), 912-923. https://doi.org/10.1002/bdra.23323

Cuquetto, D. C., Mill, J. G., \& Amaral, F. T. do. (2012). Influência do uso de fluoxetina sobre o tempo de corrida em esteira ergométrica em ratos não treinados. Revista Brasileira de Educação Física E Esporte, 26(3), 375-381. https://doi.org/10.1590/s1807-55092012000300003

Ducy, P. (2011). 5-HT and bone biology. Current Opinion in Pharmacology, 11(1), 34-38. https://doi.org/10.1016/j.coph.2011.01.007

Ducy, P., \& Karsenty, G. (2010). The two faces of serotonin in bone biology. Journal of Cell Biology, 191(1), 7-13. https://doi.org/10.1083/jcb.201006123

Feighner, J. P., \& Overø, K. (1999). Multicenter, Placebo-Controlled, Fixed-Dose Study of Citalopram in Moderate-to-Severe Depression. The Journal of Clinical Psychiatry, 60(12), 824-830. https://doi.org/10.4088/jcp.v60n1204

Fernandes, E. V., Ramos, S. de P., Estanislau, C., \& Venancio, E. J. (2012). Efeitos comportamentais e imunológicos da fluoxetina em ratos submetidos ao nado forçado. Psicologia: Teoria E Pesquisa, 28(4), 409-415. https://doi.org/10.1590/s0102-37722012000400008

Fleck, M. P., Berlim, M. T., Lafer, B., Sougey, E. B., Porto, J. A. D., Brasil, M. A., Juruena, M. F., \& Hetem, L. A. (2009). Revisão das diretrizes da Associação Médica Brasileira para o tratamento da depressão (Versão integral). Brazilian Journal of Psychiatry, 31, S7-S17. https://doi.org/10.1590/S151644462009000500003

Fleck, M. P., Berlim, M. T., Lafer, B., Sougey, E. B., Porto, J. A. D., Brasil, M. A., Juruena, M. F., \& Hetem, L. A. (2009). Revisão das diretrizes da Associação Médica Brasileira para o tratamento da depressão (Versão integral). Brazilian Journal of Psychiatry, 31, S7-S17. https://doi.org/10.1590/S151644462009000500003 
Fonseca, D. D. D. (2020). Efeitos da fluoxetina sobre a odontogênese e o desenvolvimento dos tecidos mineralizados dos dentes [Tese de doutorado].

Garlingo, LCM. Williams, JN, Li, Y., Valiya Kambrath, A., \& Sankar, U. (2018). A geração de fraturas femorais fechadas em camundongos: um modelo para estudar a cura óssea. Jornal de experimentos visualizados: JoVE, (138), 58122. https://doi.org/10.3791/58122. CSS. Patologia. Universidade Federal de Pernambuco, 2006. (sd). [Tese de mestrado].

Gartner, L. P. Hiatt, J. L., \& Al, E. (2007). Tratado de histologia em cores. Elsevier.

Gill, J. S., Jamwal, S., Kumar, P., \& Deshmukh, R. (2017). Sertraline and venlafaxine improves motor performance and neurobehavioral deficit in quinolinic acid induced Huntington's like symptoms in rats: Possible neurotransmitters modulation. Pharmacological Reports: PR, 69(2), 306-313. https://doi.org/10.1016/j.pharep.2016.11.008

Gonçalves, P. C. (2013) Efeitos do tratamento com cloridrato de fluoxetina na mandíbula da prole de ratas tratadas durante a gestação e lactação. (Dissertação de Mestrado). Universidade Federal de Pernambuco.

Henn, JD (2010). Bioquímica Do Tecido Ósseo 1. https://www.ufrgs.com.br/lacvet/restrito/pdf/osso_henn.pdf

Hodge, J. M., Wang, Y., Berk, M., Collier, F. M., Fernandes, T. J., Constable, M. J., Pasco, J. A., Dodd, S., Nicholson, G. C., Kennedy, R. L., \& Williams, L. J. (2013). Selective Serotonin Reuptake Inhibitors Inhibit Human Osteoclast and Osteoblast Formation and Function. Biological Psychiatry, 74(1), 32-39. https://doi.org/10.1016/j.biopsych.2012.11.003

Howie, R. N., Herberg, S., Durham, E., Grey, Z., Bennfors, G., Elsalanty, M., LaRue, A. C., Hill, W. D., \& Cray, J. J. (2018). Selective serotonin re-uptake inhibitor sertraline inhibits bone healing in a calvarial defect model. International Journal of Oral Science, 10(3), 25. https://doi.org/10.1038/s41368-0180026-X

Isola, J. G. M. P., \& Moraes, P. C. (2012). Estrutura e regeneração óssea - revisão de literatura. Revista científica eletrônica de Medicina Veterinária , 18.

Jaegger, IMS (2015, 21 de maio). Aspectos morfológicos e imunohistoquímico da dentinogênese e pulpogênese em prol de ratas tratadas com fluoxetina durante a gestação e lactação. Repositório. ufpe.br. https://repositorio.ufpe.br/handle/123456789/16252

Junqueira, LCU \& Carneiro, J. (2013). Histologia Básica Texto e Atlas (12ed)

Li, I-Hsun., Shih, J.-H., Jhao, Y.-T., Chen, H.-C., Chiu, C.-H., Chen, C.-F., Huang, Y.-S., Shiue, C.-Y., \& Ma, K.-H. (2019). Regulation of Noise-Induced Loss of Serotonin Transporters with Resveratrol in a Rat Model Using 4-[18F]-ADAM/Small-Animal Positron Emission Tomography. Molecules, 24(7), 1344. https://doi.org/10.3390/molecules24071344

Lirani, A. P. R. Estudo comparativo dos efeitos do ultra-som e do laser de baixa intensidade no reparo ósseo de tíbia de rato. https://doi.org/10.11606/d.82.2004.tde-04052004-091046

Matos, J. A. de B. (2011). Aspectos morfológicos do desenvolvimento do osso alveolar de filhotes de ratas tratadas com fluoxetina durante a gestação. Repositorio.ufpe.br. https://repositorio.ufpe.br/handle/123456789/8325

Mir, M., Pereira, M. A., Geonmonond, R. S., Oliveira, U. S., Araújo, T. H., \& Rossi, W. C. (2013). Uso de hidroxiapatita nanométrica em enxertos na fíbula de ratos. Ciência et Praxis, 6(11), 21-24. https://revista.uemg.br/index.php/praxys/article/view/2116

Rapport, M. M., Green, A. A., \& Page, I. H. (1948). Serum Vasoconstrictor (SEROTONIN). Journal of Biological Chemistry, 176(3), 1243-1251. https://doi.org/10.1016/s0021-9258(18)57137-4

Refsgaard, L. K., Haubro, K., Pickering, D. S., Stuart, S. A., Robinson, E. S. J., \& Andreasen, J. T. (2016). Effects of sertraline, duloxetine, vortioxetine, and idazoxan in the rat affective bias test. Psychopharmacology, 233(21-22), 3763-3770. https://doi.org/10.1007/s00213-016-4407-6

Regueira, L. S. (2013). Efeitos da fluoxetina na periodontogênese: Análise histológica e histomorfométrica em ratos. Repositorio.ufpe.br. https://repositorio.ufpe.br/handle/123456789/13120

Richter, T., Paluch, Z., \& Alusik, S. (2014). The non-antidepressant effects of citalopram: a clinician's perspective. Neuro Endocrinology Letters, 35(1), 7-12. https://pubmed.ncbi.nlm.nih.gov/24625921/

Riksen, E. A., Stunes, A. K., Kalvik, A., Gustafsson, B. I., Snead, M. L., Syversen, U., Lyngstadaas, S. P., \& Reseland, J. E. (2010). Serotonin and fluoxetine receptors are expressed in enamel organs and LS8 cells and modulate gene expression in LS8 cells. European Journal of Oral Sciences, 118(6), 566-573. https://doi.org/10.1111/j.1600-0722.2010.00778.x

Rossi Jr, W. C. (2002). Influência de uma membrana de colágeno associada a extrato etanólico de própolis na consolidação de fraturas com perda óssea (Disssertação de Doutorado). Universidade Estadual de Campinas.

Santiago, I. M. A., Regueira, L. S., Correia, P. G., Alcântara, R. J. B., Evêncio, J. N., \& Baratella-Evêncio, L. (2013) Effects of The Use of Fluoxetine Hydrochloride on the Development of Mineralized Tissues in Rats: a Systematic Review. R bras ci Saúde 17(2):181-188.

Seibel, M. J., Robins, S. P., \& Bilezikian, J. P. (2006). Dynamics of bone and cartilage metabolism: [principles and clinical applications]. Academic Press.

Silva, F. S. (2016). Hidroxiapatita carbonatada e plasma rico em plaquetas em enxertos ósseos (Dissertação de Mestrado). Universidade Federal de Alfenas.

Tarabar, A. F., Hoffman, R. S., \& Nelson, L. S. (2008). Citalopram overdose: Late presentation of torsades de pointes (TdP) with cardiac arrest. Journal of Medical Toxicology, 4(2), 101-105. https://doi.org/10.1007/bf03160963

Telles-Correia, D., Guerreiro, D. F., Oliveira, S., \& Figueira, M. L. (2007). Diferenças farmacodinâmicas e farmacocinéticas entre os SSRI: implicações na prática clínica [Differences between SSRI's pharmacokinetics and pharmacodinamics]. Acta medica portuguesa, $20(2), 167-174$. 
Research, Society and Development, v. 10, n. 17, e96101724319, 2021

(CC BY 4.0) | ISSN 2525-3409 | DOI: http://dx.doi.org/10.33448/rsd-v10i17.24319

Vestergaard, P., Rejnmark, L., \& Mosekilde, L. (2008). Selective Serotonin Reuptake Inhibitors and Other Antidepressants and Risk of Fracture. Calcified Tissue International, 82(2), 92-101. https://doi.org/10.1007/s00223-007-9099-9

Viera, A; Varotto P, V; Roim B, L; D'ottaviano R; \& Antequera, R. (2018). O efeito dos inibidores seletivos da recaptação da serotonina no metabolismo ósseo e sua influência na odontologia. ImplantNews Perio. v3(4): 675-680.

Warden, S. J., Robling, A. G., Sanders, M. S., Bliziotes, M. M., \& Turner, C. H. (2005). Inhibition of the serotonin (5-hydroxytryptamine) transporter reduces bone accrual during growth. Endocrinology, 146(2), 685-693. https://doi.org/10.1210/en.2004-1259

Williams, L. J., Berk, M., Hodge, J. M., Kotowicz, M. A., Stuart, A. L., Chandrasekaran, V., Cleminson, J., \& Pasco, J. A. (2018). Selective Serotonin Reuptake Inhibitors (SSRIs) and Markers of Bone Turnover in Men. Calcified Tissue International, 103(2), 125-130. https://doi.org/10.1007/s00223-0180398-0

Yadav, V. K., Oury, F., Suda, N., Liu, Z. W., Gao, X. B., Confavreux, C., Klemenhagen, K. C., Tanaka, K. F., Gingrich, J. A., Guo, X. E., Tecott, L. H., Mann, J. J., Hen, R., Horvath, T. L., \& Karsenty, G. (2009). A serotonin-dependent mechanism explains the leptin regulation of bone mass, appetite, and energy expenditure. Cell, 138(5), 976-989. https://doi.org/10.1016/j.cell.2009.06.051

Yadav, V. K., Ryu, J.-H., Suda, N., Tanaka, K. F., Gingrich, J. A., Schütz, G., Glorieux, F. H., Chiang, C. Y., Zajac, J. D., Insogna, K. L., Mann, J. J., Hen, R., Ducy, P., \& Karsenty, G. (2008). Lrp5 Controls Bone Formation by Inhibiting Serotonin Synthesis in the Duodenum. Cell, $135(5)$, 825-837. https://doi.org/10.1016/j.cell.2008.09.059

Yildirim, G., \& Eralp, F. E. (2021). Effect of Antidepressants and its Orthodontic Implications. Essentials of Dentistry. https://doi.org/10.5152/essentdent.2021.21005 